\title{
EL PASO PEHUENCHE Y SU APORTE AL DESARROLLO REGIONAL (1658-1846)
}

The Pehuenche Pass and its contribution to regional development

\author{
Pablo Lacoste*
}

\section{RESUMEN}

Se examina la evolución histórica del Paso Pehuenche en sus dos primeros siglos de historia (XVII-XIX). Se detecta la constante voluntad de los pueblos de la tierra de abrir el camino para establecer vínculos económicos, sociales y culturales a ambos lados de la cordillera de los Andes. También se percibe la tendencia de las autoridades a restringir la ruta trasandina mediante medidas político-administrativas y castigos a los transgresores. A pesar de la resistencia oficial, estos grupos promovieron la circulación de bienes y personas por el Paso Pehuenche, con lo cual activaron la economía regional y fortalecieron el patrimonio alimentario y artesanal. Al estudio se realiza una revisión bibliográfica del tema y con nuevas lecturas de documentos de la época, principalmente el juicio al malón de 1658.

Palabras clave: Corredores bioceánicos, caminos trasandinos, integración regional, desarrollo económico regional, patrimonio alimentario.

\footnotetext{
* Universidad de Santiago de Chile. Santiago, Chile. Correo electrónico: pablo.lacoste@usach.cl Recibido el 19 de agosto de 2017. Aceptado el 23 de enero de 2018.
} 


\begin{abstract}
The historical evolution of the Pehuenche Pass in its first two centuries of history (XVII-XIX) is examined. On the one hand, the constant will of the indigenous and mestizo peoples is detected by April the way to establish economic, social and cultural links on both sides of the mountain range. On the other hand, the tendency of the authorities to restrict the road through political-administrative measures is perceived. Despite the official resistance, these groups promoted the circulation of goods and people through the Pehuenche Pass, thereby activating the regional economy and strengthening the food and artisan heritage. To the study a bibliographical revision of the subject is made and with new readings of documents of the time, mainly the judgment to the malon of 1658 .
\end{abstract}

Keywords: Bioceanic corridors, trans-Andean roads, regional integration, regional economic development, food heritage.

El Paso Pehuenche permite la conexión e integración física entre la región del Maule (Chile) y la provincia de Mendoza (Argentina), en el corazón de la cordillera de los Andes, en latitud de $36^{\circ}$ sur. A través de este boquete se ha construido una carretera internacional, librada al servicio completamente pavimentada en 2016. A partir de entonces, el flujo de personas a través de este camino ha evolucionado en forma creciente (MOP, 2017), Esta obra representa la culminación de un largo proceso histórico, signado por la tensión entre la actitud restrictiva de las élites, y la demanda de apertura del camino por parte de los pueblos de la tierra.

El presente artículo pretende aportar al conocimiento de la historia e identidad de este camino, desde la perspectiva de la tensión entre los actores locales y los poderes centrales. Desde esta perspectiva, se estudian los dos primeros siglos de historia de esta ruta, desde su descubrimiento por parte de los Pehuenches (1658) hasta las regulaciones establecidas por los gobiernos republicanos de mediados del siglo XIX (1848). Dentro de ese lapso de dos siglos, se examinan críticamente los antecedentes disponibles, incluyendo 
los relatos de cronistas y viajeros (Amat y Junient, Juan de la Cruz, Manuel Pueyrredón) y la bibliografía especializada (Rojas, 1940; Comadrán Ruiz, 1962 y 1983; Sosa Morales, 1965; Donoso, 1966; Bustos Dávila, 1972; Villalobos, 1989; Silva, 1990; Maza, 1991; Prieto, 2000; León, 2001; Retamal, 2004; Escolar, 2006; Vera, 2003 y 2011). Estas obras dan cuenta de la situación de los pueblos situados a ambos lados de la cordillera de los Andes en aquella época. La circulación por los pasos trasandinos no estuvo en el foco de esas obras; y ese es justamente, el aporte original que brinda el presente estudio.

Sobre la base de este corpus literario-documental, se ha elaborado el presente texto, en el cual se percibe con claridad el patrón de conductas divergentes: por un lado, las élites trataron sistemáticamente de restringir el camino; por otro, los pueblos de la tierra alentaron la circulación a través del Paso Pehuenche, con vistas a articular la integración y el desarrollo económico, social y cultural de la región afectada. Los intercambios a través de este boquete contribuyeron al fortalecimiento del patrimonio agroalimentario y artesanal de la región, incluyendo alimentos (como queso de Chanco) e indumentaria (ponchos, chamantos, chupallas). El surgimiento de estos productos ha sido estudiado por la literatura especializada (Aguilera, 2015; Núñez, 2016; Castro, 2017). En este artículo se aporta un elemento nuevo, al destacar al aporte de la circulación por Paso Pehuenche al desarrollo de los productos patrimoniales. Para profundizar en este tema, el estudio examina en detalle la documentación del Paso Pehuenche, principalmente el juicio al malón (1658), que representa la más rica fuente disponible sobre este paso.

La historia del Paso Pehuenche comenzó con un hecho gastronómico: la comida servida en el Capu-mallu (cerro Campanario) entre los anfitriones puelches y sus visitantes pehuenches, llegados del Valle Central de Chile. La ceremonia se realizó con los rituales habituales de los parlamentos, celebración de singular relevancia en el mundo indígena, equivalentes a los Tratados Internacionales entre Estados modernos (Levaggi, 2000). 
El alimento era el centro de la celebración y se sirvió con generosidad ${ }^{1}$. En aquellos años, se estimaba que este animal alcanzaba para alimentar a doscientas personas (Da Vinci, 2013). El cálculo era suficiente para alimentar 50 puelches, 100 pehuenches y las familias de la toldería. La carne no consumida se conservó en forma de charqui. La comida sirvió para conformar el escenario y realizar el ritual. "Cuando mataron el caballo, los pehuenches se juntaron en rueda y su hermano (Yoyarric) y los demás, en agradecimiento de la muerte del caballo escaramucearon con su gente y se entraron al parlamento"2. La apertura del Paso Pehuenche era un hecho trascendental, y debía acordarse en un marco de solemnidad, legitimada por una comida en común.

Además del alimento, la ceremonia se fortalecía con los regalos, sobre todo mantas y tejidos. "Los pehuenches les dieron a los puelches camisetas y mantas e hilados"3. La abundancia de comidas y regalos generó un ambiente de celebración notable. La ceremonia se prolongó por cuatro días ${ }^{4}$. En este contexto, se consolidó el primer encuentro de confraternidad entre dos pueblos, el cual abrió el camino a la circulación por el Paso Pehuenche, activó los intercambios trasandinos y estimuló el desarrollo del patrimonio agroalimentario regional.

La base de la economía puelche era el ganado. Los fuertes vientos y bajas temperaturas de la zona desalentaban la práctica de la agricultura. Pero sí se podían criar animales, sobre todo caballos y ovejas. El caballo les ofrecía movilidad para sus largos viajes, y alimento. Los puelches apreciaban la carne de caballo y en las fiestas, no dudaban en sacrificar un animal para realizar un banquete. La carne que no se consumía en el día, se conservaba por medio

\footnotetext{
${ }^{1}$ Declaración de Juanillo, hermano de Yoyarric, 11 de agosto de 1658. Juicio p. 27.

${ }^{2}$ Declaración de Juanillo, 11 de agosto de 1658. Juicio p. 27.

${ }^{3}$ Escrito del Juan Alonso de Agüero, solicitador del fisco y en defensa de la Justicia contra don Bartolo y su hermano y demás indios. Juicio (1928: 48).

${ }^{4}$ Declaración de Pedro García, Mendoza, 10 de agosto de 1658. Juicio, p. 7.
} 
de deshidratación. La acción se llamaba "charquiar" y el resultado, charqui, permitía asegurar el alimento por largo tiempo ${ }^{5}$.

Para manejar los animales, los puelches construían corrales con piedras. Y estas pircas se convirtieron en referentes del paisaje cultural. Así lo manifestó el indio Balta Chontal: preguntado sobre la localización de las tierras de Yoyarri, dijo que "su tierra era en el corral arriba de la laguna". Otros declarantes coincidieron en mencionar estas construcciones: "Los pehuenches dejaron los caballos en la Laguna Grande donde está el corral para que engordasen para comerlos"7. La expresión "corral de piedra", Malal hue, formó parte de la toponimia local, y culminó con la adopción de este nombre para llamar al departamento de Malargüe.

La abundancia de agua facilitaba el desarrollo de la fauna y flora silvestre, la cual también aportaba a la vida de los puelches. Estos cazaban guanacos y liebres; recogían algarroba y raíces para obtener harina. Los puelches eran hábiles talabarteros. Con cueros de guanacos y liebres manufacturaban recipientes utilitarios como zurrones para almacenar alimentos y cantimploras para transporta agua en sus largos viajes ${ }^{89}$.

La sal y las salinas eran un recurso abundante en el sur de Mendoza. Los puelches la usaban para trabajar sus cueros y conservar sus alimentos, sobre todo el charqui. Las salinas se convirtieron en referentes de sus paisajes y parte de su vida cotidiana. En los relatos del juicio se mencionan recurrentemente las salinas. "En las salinas habían hablado con un cacique", refirió uno de los testigos ${ }^{10}$. Otro relato también menciona esta referencia: “don Bartolo llegó

\footnotetext{
${ }^{5}$ Declaración de Pedro García, Mendoza, 10 de agosto de 1658. Juicio, p. 5.

${ }^{6}$ Declaración de Balta Chontal, indio morcoyano, Mendoza, 13 de agosto de 1658. Juicio p. 39.

${ }^{7}$ Declaración de Cayla, hechicero puelche, posteriormente ahorcado, Mendoza, 13 de agosto de 1658. Juicio p. 41.

${ }^{8}$ Declaración de Pedro García, Mendoza, 10 de agosto de 1658. Juicio, p. 5.

${ }^{9}$ Declaración de Pedro García, Mendoza, 10 de agosto de 1658. Juicio, p. 8.

${ }^{10}$ Declaración de Cayla, hechicero puelche, luego ahorcado. Mendoza, 13 de agosto de 1658. Juicio p. 42.
} 
a las salinas por su mismo rastro; había venido con los pehuenches"11. Estos recursos tenían un potencial que en ese momento, todavía no se percibía con claridad.

El resultado del parlamento del Capu-mallu fue la apertura de este corredor trasandino para los pehuenches. Los indígenas comenzaron a circular por este camino para intercambiar bienes y servicios entre ambas bandas de la cordillera. Se abrió un nuevo ducto, llamado a contribuir al desarrollo de la región del Maule, sus productos típicos y su patrimonio gastronómico y artesanal.

El cambio ocurrió de forma lenta, debido al pequeño tamaño de los mercados y la renuencia de los españoles a activar los caminos trasandinos. El miedo paralizaba a las autoridades de Chile y Cuyo, y se reiteraban las medidas restrictivas. Como resultado del juicio al malón de 1658, se condenó a muerte a diez pehuenches y a los jefes puelches, como medio de amedrentamiento. Con los años, la política restrictiva se reiteró. En el parlamento de Tapihue (1746) se acordó la prohibición de circular por los pasos cordilleranos de Chillán, Maule (paso Pehuenche) y Colchagua (paso Las Damas) (Villalobos, 1989: 42).

A pesar de las prohibiciones de los españoles, los pasos se mantuvieron vivos. A través de ellos, los indígenas y mestizos transportaban bienes entre ambos lados de la cordillera. Hasta ahora, los bienes más visibles de este comercio han sido ganado y tejidos; fue importante el intercambio de estos últimos, en el marco de la ruta del poncho en el Cono Sur, tema estudiado en otra parte. A ello hay que sumar otro producto que, hasta ahora, ha sido menos visible: la sal.

La economía de la región del Maule necesitaba sal para múltiples funciones. De acuerdo a los informes oficiales de Francisco de Madariaga y luego, de José Fernández Campino (1744), la economía del Maule se apoyaba principalmente en la ganadería, con la crianza de 22.000 vacunos,

\footnotetext{
${ }^{11}$ Declaración del cacique Juan, Mendoza, 15 de setiembre de 1658. Juicio p. 66.
} 
55.000 caprinos y 150.000 ovinos. Sobre esta base se elaboraban numerosos subproductos, principalmente cueros curtidos (cordobanes) y carne deshidratada (charqui). Productos destinados tanto al mercado chileno como a la exportación hacia Perú y Potosí. Y justamente para asegurar este modelo productivo se necesitaban campos de pastura para el ganado, y sal para elaborar subproductos: tanto los cordobanes como el charqui requieren grandes cantidades de sal. A ello se sumaban el uso para elaborar los famosos quesos de Chanco, actividad que experimentó un fuerte ascenso desde comienzos en esos años.

En Chile, la principal producción de sal se encontraba en el borde costero del Corregimiento de Colchagua, sobre todo en Boyeruca, Bucalemu y Cáhuil. Desde allí, por el camino de la sal, los arrieros abastecían la demanda de los mercados metropolitanos. La producción de sal de costa chilena fue relevante en los siglos XVII, XVIII y XIX (Vera, 2003 y 2011; Lacoste Adunka, 2017). De todos modos, esta oferta era insuficiente para satisfacer la demanda chilena; por este motivo, se buscaron otras fuentes de abastecimiento, tanto en Perú como al otro lado de la cordillera, particularmente de las salinas surmendocinas.

La sal trasandina se consolidó entre los principales productos del comercio regional. Como los pehuenches vivían en la montaña, y allí no era posible la agricultura, necesitaban la sal para asegurarse el acceso al trigo como alimento central, provisto por los hispanocriollos. Así lo detectó el intendente de Concepción, Juan de la Cruz, en su viaje exploratorio de 1806. "Los granos que nos permutan es por sal, caballos, vacas, ovejas, ponchos, mantas, etcétera" (Cruz, 1969: 487).

Los boquetes cordilleranos facilitaron el acceso de la sal surmendocina a los mercados maulinos. A pesar de las restricciones impuestas por el Estado, los arrieros indígenas se las arreglaban para asegurar el transporte de sal y el abastecimiento de los mercados regionales. Un informe oficial, elevado al Rey por el gobernador de Chile (1760), reconoció estos flujos comerciales: 
Por el desembocadero de Tinguiririca, Teno, el Huayco y Lontué, tienen salida, y entrada los indios Chiquillanes, que habitan entre las cordilleras. Son estos indios salvajes, y bárbaros, sin trato con los españoles, sino a ciertos tiempos, en que los más fronterizos comercian la sal, que cuaja en abundancia, y muy sabrosa en las grandes lagunas, que tienen en los valles que cierran las cordilleras. Aliméntense estos indios de toda especie de carnes, sin reservar los caballos y yeguas, y transitan de una y otra parte las cordilleras, mudando las tolderías (Amat y Junient, 1925: 443-444).

Resulta notable la doble actitud del gobierno con respecto al comercio trasandino de la sal: por un lado, prohibía la circulación por los boquetes para priorizar la seguridad; por otro, admitía la existencia de flujos comerciales a través de esos pasos, y su aporte al desarrollo regional. Esta dicotomía mantenía el transporte de la sal en una zona gris de semipenumbra. Era difícil registrar oficialmente esta actividad, dado su carácter clandestino. De todos modos, el transporte de sal trasandina hacia el Maule tendió a consolidarse con el tiempo. Vera (2003) detectó que entre 1760 y 1787 se otorgaron oficialmente 19 permisos para internar 7.116 cargas de sal por el paso Planchón.

La sal se consolidó entre los principales productos del comercio regional. Como los pehuenches vivían en la montaña, y allí no era posible la agricultura, necesitaban la sal para asegurarse el acceso al trigo como alimento central, provisto por los hispanocriollos. La relevancia de las salinas surmendocinas fue también argumento para impulsar la creación de ciudades en la zona. Así se refleja en el proyecto de traslado de la frontera hispanocriolla al sur, elaborado por el comerciante y militar Sebastián Undiano y Gastelú en 1796. En este documento, el autor menciona las riquezas de la zona como argumento para justificar la inversión que implicaban los nuevos asentamientos. Entre los recursos más relevantes, destaca las salinas: "Buenas muestras de ricos minerales en la sierra inmediata del oeste, y unas salinas inagotables de excelente sal en sus inmediaciones, es lo que ofrece ese bello paraje a la vista" (Undiano y Gastelú, 1969: 508-509).

El intercambio de sal, ganado y ponchos consolidó la presencia de los 
pehuenches en las montañas. La zona del Paso Pehuenche fue su principal asentamiento. Así lo comprobó el comandante Amigorena en 1780, cuando llegó con una fuerza de 600 tropas a las tolderías del paso pehuenche. "Estas se ubicaban en el paraje llamado Campanario, al pie del mismo nombre, en plena cordillera" (Sosa, 1965: 17). "En esta forma logaron avistar, al pie del cerro Campanario, las tolderías indígenas" (Maza, 1991: 37). Allí estableció contacto con el principal toqui pehuenche, Güentenao. Se produjeron conflictos violentos en la zona. Las tropas españolas mataron 116 indígenas, tomaron 123 prisioneros y secuestraron ganado: 99 equinos, 200 caprinos y 1.114 ovinos (Sosa, 1965: 18). Estos registros muestran la relevancia alcanzado por los pastores en esta zona.

A partir de este encuentro violento, se comenzaron a construir relaciones pacíficas, consolidadas con parlamentos y tratados. Poco a poco, el Paso Pehuenche se consolidaba como parte del escenario diplomático y comercial en la región. Así lo señala historiografía especializada: “Al promediar el año 1783, informado de que nuevamente Ancán Amún se encuentra establecida en las inmediaciones del Campanario con toda su gente, (el comandante Amigorena) envía al cacique Llancopán para requerirle viniese a la ciudad a tratar la paz y amistad" (Sosa, 1965: 26).

El viaje de Ancán Amún desde el Campanario hasta Mendoza para reunirse con las autoridades españolas, culminó con el Tratado de Paz del 24 de octubre de 1783. Este acuerdo marcó un hito relevante en el proceso de sustitución de la guerra por la diplomacia, la paz y el comercio. Desde Buenos Aires, el virrey Vértiz celebró el Tratado de Paz de 1783 alcanzado con los pehuenches: "quedo enterado de la paz que celebró con el cacique Ancan o Ancanamun que después de haber igual diligencia en Chile, pasó a establecerse en las inmediaciones del paraje nombrado de Campanario" (León, 2001: 123).

A través de este acuerdo, se abrió el camino a la llamada política de los caciques gobernadores. Este fue el resultado de pacientes tratativas diplomáticas 
lideradas por Ambrosio O'Higgins en Chile y José Francisco Amigorena en Cuyo. A través de complejos ceremoniales, los hispanocriollos lograron establecer el reconocimiento de una autoridad pehuenche para asegurar el control del sur de Mendoza y los pasos cordilleranos. Este fue el papel de Ancan Amún (1785-1787), se hermano Pichintur (1787-1795), el hijo del primero, Millanguir (1795-1797) y Pichicolemilla (1797). El cargo de gobernador estaba rodeado del prestigio y la distinción; la construcción de esta institucionalidad fue funcional al proceso de construcción de la paz en la frontera (Maza, 1991: 43-52; León, 2001).

La necesidad de intercambio comercial a través de la cordillera, facilitó el poblamiento de las montañas lo cual, a su vez, impulsó la colonización, la ocupación de espacio y la actividad económica. Las relaciones entre hispanocriollos e indígenas se estrecharon, a veces en forma violenta, y otras con modos diplomáticos. "Un nuevo parlamento firmado en 1794 con los derrotados en Nuyegalei dos años antes, amplió la frontera y aseguró las comunicaciones con Chile por el sur" (Comadrán Ruiz, 1962: 239). Lentamente, se generaron las condiciones para fundar San Rafael.

La articulación de los pehuenches con los grupos hispanocriollos de Mendoza, generó las condiciones para consolidar la colonización del territorio a la vida social y económica, proceso que culminó en 1805 con la fundación del Fuerte de San Rafael, nueva capital del sur de Mendoza. El nacimiento de esta ciudad se concretó en el marco de un parlamento celebrado entre las autoridades españolas y los pehuenches, representados estos por 23 caciques y 11 capitanejos. El parlamento tuvo lugar en la confluencia de los ríos Diamante y Atuel, y en su artículo 6 dice textualmente que los indígenas: "Ratificaron su allanamiento a que abramos especialmente el camino a Talca, facilitándoseles así el comercio sin salir de sus tierras” (Bustos Dávila 1972: 700).

El corredor bioceánico por el Paso Pehuenche se hizo cada vez más visible en las élites de ambos países, tanto en Buenos Aires como en Santiago de Chile. Fue tema de análisis entre los referentes de la época, como Manuel 
Belgrano y Manuel de Salas respectivamente. En la correspondencia que sostuvieron entre ellos para coordinar acciones de carácter económico y social, el Paso Pehuenche estuvo presente. En carta del 16 de setiembre de 1805, Belgrano escribió a Salas:

Nada me dice usted del nuevo camino a Talca. Al fin sabemos que hay paso por la cordillera para carretas. Con mucho gusto mío veo la competencia de los talquinos y penquistas, aspirando cada uno a llevar el camino por su territorio, pues de este modo conseguiremos comunicación por todas partes con esas fértiles provincias y podremos auxiliarnos mutuamente. Cerro y Zamudio tendrá siempre el mérito de haber promovido estas empresas y espero verlas realizadas en mejores circunstancias (Bustos Dávila, 1972: 692).

La fundación de San Rafael significó un avance relevante en el proceso de colonización del sur de Mendoza y generó un lugar de abastecimiento para los arrieros que circulaban a través de la cordillera rumbo a Talca. Lentamente se avanzó en la ocupación del espacio, con hitos como la fundación del fuerte de Malalhue poco después (Maza, 1991). Estos asentamientos mejoraron la seguridad y la infraestructura de servicios y abastecimiento, lo cual facilitó la circulación por el Paso Pehuenche y el desarrollo de los sujetos históricos específicos, como pastores, arrieros, tejedoras, talabarteros y maestros queseros.

Los pastores tenían la oportunidad de alimentar sus cabras y ovejas en las veranadas, cuando la nieve se derretía y aparecían las ricas praderas en los valles intermontanos, particularmente en la cuenca del río Grande. Se consolidó entonces una cultura trashumante, formada por pastores que realizaban periódicamente movimientos de ascenso y descenso de las montañas, por estos caminos, con el objetivo principal de alimentar sus ganados. Esta actividad alcanzó magnitudes significativas, las cuales llevaron a los gobiernos de Argentina y Chile, en el segundo tercio del siglo XIX, a establecer una serie de acuerdos diplomáticos con vistas a reglamentar el uso de los recursos naturales del lado argentino, por parte de los pastores chilenos (Comadrán Ruiz, 1983). 
El segundo actor significativo de estos paisajes fue el arriero. Sus viajes eran más largos que los de los pastores, porque apuntaban a conectar mercados. El arriero partía, por lo general, de las ciudades chilenas de la región del Maule, cruzaba la cordillera por el Paso Pehuenche y entraba en contacto con los grupos humanos de la falda oriental de los Andes para intercambiar bienes. Sus viajes podían demorar largo tiempo, incluso semanas o meses. El tramo de alta montaña resultaba exigente y áspero, con pocos recursos para sustentarse, y bajas temperaturas, sobre todo de noche y en invierno (Pueyrredón, 1947).

Para afrontar los desafíos de la alta montaña, el arriero desarrolló un equipaje cada vez más complejo y eficiente. Para abrigarse, usaba ponchos impermeables, capaces de resistir la lluvia y la nieve. Para protegerse del sol, usaba chupallas de paja, que también debían cuidarlo de la lluvia, mediante tejidos cada vez más finos e impermeables. Además, el arriero necesitaba petacas de cuero para transportar sus cargas sobre las mulas; y los aperos necesarios para mantener en buenas condiciones de equilibrio estas cargas, junto con los juegos de riendas, monturas y estribos. Al demandar constantemente estos objetos, el arriero estimuló la producción artesanal de talabartería, tejidos especiales y sombreros huasos. Como sujeto histórico, el arriero contribuyó al surgimiento y consolidación de productos típicos chilenos, como chamantos y chupallas (Castro 2017; Núñez, 2017).

La alimentación del arriero fue otro vector para estimular el desarrollo económico, social y cultural de la región. Para beber, se usaba la calabaza romana, o cantimplora arriera. Este era un recipiente elaborado a partir de una variedad especial de calabaza. Los artesanos aprendieron a prepararla para su uso como recipiente de líquidos, incluyendo vino o agua. Para el arriero, estas calabazas eran muy útiles por ser muy livianas $\mathrm{y}$, a la vez, tener gran capacidad (entre 5 y 8 litros). Con estas cantimploras, el arriero podía cabalgar toda la jornada, sin necesidad de descender al río Tinguiririca o al río Grande para abastecerse de agua. A ello se sumaban los alimentos: quesos, charqui, ají, cebolla, ajo, 
pimientos deshidratados, harina tostada y otros productos formaban parte de su dieta habitual. Las cebollas eran indispensables en la montaña para prevenir el mal de altura tanto para él como para sus mulas (Pueyrredón, 1947: 136). La leche no la podía conservar largo tiempo; por este motivo, era mejor llevar queso. De este modo se aseguraba la provisión de calcio; y para obtener proteínas, consumía el charqui. Durante la marcha, el arriero podía comer pequeñas porciones, pero al final de cada jornada, tras descargar las mulas y asentar su campamento, el arriero se daba el tiempo para calentar agua en su olla de cobre labrado y preparar con calma el valdiviano u otras formas de ajiaco. A pesar de la adversidad del medio, el arriero logró desarrollar una gastronomía muy bien adaptada. Estos usos y costumbres, surgieron como adaptación del arriero a los paisajes de montaña. Posteriormente, fueron utilizados por el Ejército de los Andes, en 1817, para realizar las campañas libertadoras y asegurar la independencia de Argentina y Chile (Pueyrredón, 1863; Rojas, 1940: 163).

Tal como ocurría con las artesanías, el arriero impulsó también la producción de alimentos y la gastronomía regionales. Su demanda de harina tostada contribuyó a alentar el establecimiento de molinos harineros: en sus precarias condiciones, el arriero no podía dedicar una hora de trabajo, en alta montaña, para moler el trigo necesario para una comida de su tropa cada día. Por tal motivo, requería llevar consigo la harina ya preparada. También contribuyó a alentar las mejoras técnicas en la elaboración de otros alimentos, como charqui, hortalizas deshidratadas y quesos. El surgimiento del chancho en piedra (tomate chancado en piedra de moler), surgió en el marco de este contexto cultural. Y lo mismo ocurrió con los quesos de Chanco (Aguilera, 2016).

El maestro quesero fue otro sujeto histórico impulsado por la apertura de los caminos cordilleranos, particularmente por su capacidad de elaborar el famoso queso de Chanco. Junto con el vino asoleado de Cauquenes, el queso de Chanco fue el producto estrella de la región del Maule durante más de 200 años. Era un queso curado, elaborado a partir de leche de oveja (Aguilera, 2016) 
y, originalmente, sal de Cáhuil (Lacoste Adunka, 2017). Surgió a comienzos del siglo XVII, en el borde costero de la actual provincia de Cardenal Caro, cerca de las salinas de Cáhuil, Bucalemu y Boyeruca. La presencia de ganado ovino y sal de costa, generó las condiciones para el surgimiento del queso local, fuertemente demandado por los mercados metropolitanos. En los siglos XVII y XVIII, los arrieros llevaban estos quesos hasta Santiago, por el llamado "camino de la costa" o "camino de la sal". Este camino se prolongaba también hacia el sur, llegaba al puerto de Nueva Bilbao (luego Constitución), cruzaba el Maule, y entraba en la entonces llamada "Doctrina de Chanco", territorio parecido a la actual provincia de Cauquenes. La sal de costa, originaria de Cáhuil y sus alrededores, llegó a estas tierras, donde abundaba el ganado ovino; y la disponibilidad de ambos productos facilitó el surgimiento de la cultura de elaboración de quesos, en cantidades cada vez más importantes. Allí, este producto adoptó el nombre de "queso de Chanco", debido a la relevancia de la entonces importante "Doctrina de Chanco". Los campesinos aprovechaban también las facilidades de la cuenca de los ríos Loncomilla y Maule, para sacar su producción quesera hacia los mercados externos, a través del puerto de Constitución. El queso de Chanco fue identificado en el siglo XVIII por el abate Molina, y luego, se hizo famoso en la región, sobre todo por sus exportaciones hacia Lima, Guayaquil y California. El tema es ampliamente estudiado en otra parte (Lacoste et al., 2014 y 2015; Aguilera, 2016). Ahora lo interesante es destacar el papel que cupo a la sal surmendocina en el proceso de consolidación y expansión del queso de Chanco, lo cual fue posible gracias al Paso Pehuenche.

La presencia de los pastores maulinos en los valles intermontanos de la zona del Paso Pehuenche, junto al río Grande, se hizo visible en la década de 1840, con motivo de los derechos soberanos sobre los valles contiguos al río Grande. Las fronteras y límites no estaban todavía fehacientemente establecidos, y ambos gobiernos consideraban propios estos valles, Argentina por hallarse aquellos al oriente del encadenamiento principal de la cordillera y 
Chile por la presencia ancestral de los pastores y arrieros maulinos.

En estas circunstancias confusas todavía, el cuestionado gobernador Félix Aldao emitió dos instrumentos jurídicos que tensaron el ambiente en la zona. Por un lado, resolvió premiar la lealtad y los servicios prestados por el coronel Juan Antonio "huaso" Rodríguez, de origen colchagüino pero jefe del fuerte de San Rafael desde 1839. Para gratificarlo le concedió en propiedad tierras fiscales de frontera, incluyendo los terrenos conocidos como "el Chacay y los potreros de cordillera" (Maza, 1991 : 135). Poco después, el 5 de setiembre de 1843, Aldao emitió un decreto por el cual se cobrarían impuestos de talaje a los pastores en esos valles y nombró como autoridad de aplicación al mismo Rodríguez.

Las acciones del gobierno de Mendoza en terrenos de fronteras indefinidas, causaron respuestas en Chile. Rodríguez comenzó a presionar a los pastores maulinos con este impuesto, so pena de confiscar sus animales. Ante las quejas de los pastores, el gobierno de Chile salió en su defensa, y por decreto del 18 de febrero de 1846 facultó “al Intendente de Talca para facilitar la fuerza pública para la protección de los ganaderos chilenos" (Donoso, 1966: 312). En estas condiciones contradictorias, el choque cruento en la zona se hizo inevitable.

La zona del Paso Pehuenche volvió al centro de la escena binacional en el verano de 1847, cuando se encontraron ambas fuerzas. Desde el fuerte San Rafael, el huaso Rodríguez envió al también chileno Domingo Muñoz, con un grupo de personas, para cobrar los impuestos en los valles Yeso, Valenzuela, Los Ángeles y Montañés. En la zona llamada "Casa del Yeso", propiedad de la familia chilena Girón, los delegados de San Rafael tomaron contacto con los pastores maulinos y exigieron el pago del impuesto, so pena de confiscación de animales. Los pastores acudieron al administrador de los terrenos, Agustín Labra, el cual resolvió rechazar por la fuerza a los cobradores. Se produjo entonces un enfrentamiento armado, en el cual resultaron heridos Domingo 
Muñoz (dos hachazos y una puñalada) y dos de sus compañeros (heridos de bala) (Comadrán Ruiz, 1983: 14). Una vez sometidos sus adversarios, Labra los capturó, envió a Talca y entregó a la justicia.

La escalada del conflicto de los valles del río Grande, permitió visibilizar la presencia ancestral de los pastores y arrieros maulinos en la zona. Las autoridades canalizaron el conflicto por vía diplomática y se procedió a esclarecer la cuestión de la soberanía territorial en el área. Finalmente se comprobó que esos valles correspondían a Argentina y se liberó a Muñoz y sus prisioneros (Comadrán Ruiz, 1983: 15). La fundación de la villa El Milagro en el paraje llamado El Chacay, base de la futura villa de Malargüe, fue también una respuesta a estos hechos. En 1847, El Milagro tenía 216 pobladores (Maza, 1991: 136).

Paralelamente, las relaciones bilaterales se tensaron por las tendencias autoritarias del gobierno del dictador Rosas, lo cual derivó en el cierre oficial del comercio cordillerano por el paso oficial de Uspallata durante cinco años (1842-1846). En ese lapso, cuando las relaciones de Estado a Estado estaban deterioradas, el Paso Pehuenche sirvió para mantener vivas las relaciones de pueblo a pueblo. En efecto, en esos cinco años de fronteras bloqueadas, los arrieros maulinos y surmendocinos lograron mantener vivo el comercio binacional a través de los menos vigilados pasos del Planchón y Pehuenche (Comadrán Ruiz, 1983). De este modo renació la antigua costumbre de utilizar esos caminos para vincular a los pueblos, en abierto desafío a los intereses y medidas restrictivas impuestas por los poderes centrales.

La normalización de las relaciones diplomáticas entre Argentina y Chile comenzó, lentamente, en 1846, después de la muerte del fraile Aldao. Su sucesor en el gobierno de Mendoza depuso las medidas autoritarias contra los residentes chilenos, y el gobierno de Santiago levantó las medidas restrictivas a la circulación comercial bilateral. Como resultado, se reactivó el corredor por Uspallata; paradójicamente, a partir de entonces, se redoblaron las medidas 
para restringir los pasos entre el Maule y el sur de Mendoza. Así lo estableció el gobernador de Mendoza por decreto del 30 de diciembre de 1846, en el cual se señalaba lo siguiente:

Art. $1^{\circ}$ No podrá haber introducción de artículos comerciales de la República de Chile por los caminos del Portillo, el Planchón y otros que ofrecen las cordilleras del sur de la provincia y por el norte por el conocido de los Patos.

Art $2^{\circ}$ Las introducciones de efectos manufacturados y otros artículos comerciales de la República de Chile se harán precisamente por el camino denominado de Uspallata. Toda importación o exportación por cualquiera otro boquete de Cordillera será declarada en comiso (Comadrán, 1983: 22).

La decisión del gobernador de Mendoza, en el sentido de ordenar el cierre de los pasos del sur de la provincia, afectaba directamente a los boquetes del Planchón y el Pehuenche. Esta decisión de 1846 estaba en línea con las decisiones de 1658, 1746 y otras similares. Las autoridades de gobierno preferían cerrar los caminos por miedo a los efectos que pudiera generar su activación. Desde la visión del poder, el Paso Pehuenche era un camino incómodo, capaz de generar dificultades y problemas. Los gobernantes no fueron capaces de advertir el profundo sentido dinamizador que tenía este corredor.

Los dos primeros siglos de historia del Paso Pehuenche reflejaron con claridad la divergencia de actitudes entre las élites y los pueblos del lugar. Desde el poder, los gobernantes tendían a restringir la circulación por el camino y castigar a los que atravesaban la cordillera por esta zona; los documentos de 1658, 1746 y 1847 muestran la tendencia restrictiva de las autoridades. La acción restrictiva de las autoridades contrastaba con los reclamos de los actores sociales subalternos. Hubo una fuerza silenciosa, gestada desde esas montañas por arrieros, pastores y otros grupos. A diferencia de la desconfianza de las autoridades, los actores locales supieron aprovechar el Paso Pehuenche para formar redes sociales y económicas, ocupar el espacio, articular recursos y fortalecer el patrimonio alimentario y artesanal de la región, representado por 
chupallas, chamantos y cordobanes; quesos de Chanco, charqui y valdiviano, entre otros productos. Los efectos positivos eran evidentes para los pueblos asentados a ambos lados de la cordillera, tanto en el Maule como en el sur mendocino, particularmente sujetos históricos relevantes como arrieros, pastores, tejedoras, talabarteros y maestros queseros.

\section{Referencias}

Aguilera, Paulette (2016). "El queso de Chanco: un producto típico de la industria popular de Chile (siglos XVIII y XIX)". RIVAR, 3 (8), 41-63.

Amat y Junient, Manuel (1925-26). “Historia geográfica e hidrográfica. Revista Chilena de Historia y Geografía con derrotero general correlativo al plan del Reino de Chile que remite a nuestro monarca Carlos III". Revista Chilena de Historia y Geografia, 51 (55), 425-458.

Bustos Dávila, Nicolás (1972). "Fuerte San Rafael del Diamante. Su ciclo histórico (1805-1879)". Revista de la Junta de Estudios Históricos de Mendoza, II (7), 685-707.

Castro, Amalia et al. (2017). "Chamantos y mantas corraleras de Doñihue: ascenso y consolidación de un textil con Denominación de Origen (1917-2016)". RIVAR, 4 (11), 4-30.

Cruz, Juan de la (1969). "Descripción de la naturaleza de los terrenos que se comprenden en los Andes poseídos por los pehuenches y los demás espacios hasta el río de Chadileubu". En Pedro De Ángelis. Colección de Obras y Documentos (pp. 399-491). Buenos Aires, Plus Ultra, tomo II.

Comadrán Ruiz, Jorge (1962). “Nacimiento y desarrollo de los núcleos urbanos y del poblamiento de la campaña del país de Cuyo durante la época hispana (1551-1810)". Anuario de Estudios Americanos 19, 145-246.

Comadrán Ruiz, Jorge (1983). "Mendoza y las relaciones con Chile durante la época de Rosas". Nuestra Historia, Revista de Occidente, 16 (31-32), $3-28$.

Da Vinci, Leonardo (2013). Apuntes de cocina. Pensamientos, misceláneas y fábulas. $3^{\mathrm{a}}$ edición. Buenos Aires: Andrómeda. 
Donoso, Ricardo (1966). “La mejor espada del fraile Aldao: el huaso Rodríguez”. Revista de la Junta de Estudios Históricos de Mendoza, 307-323.

Escolar, Diego (2006). “¿Mestizaje sin mestizos? Etnogénesis huarpe, campo intelectual y regímenes de visibilidad en Cuyo, 1920-1940". Anuario IEHS, 21, 151-179.

Juicio al malón de 1658. Proceso Criminal instaurado por las autoridades de Cuyo contra las cuadrillas de indios Puelches y Pehuenches y no pocos aucaes o bellacos procedentes del otro lado de la Cordillera. En Pablo Cabrera (1928). "Aborígenes del país de Cuyo". Revista de la Universidad Nacional de Córdoba, 15 (7-8), 47-51; 1929, 16 (1-2), 3-112.

Lacoste Adunka, Michelle y Lacoste, Pablo (2017). "Sal de Cáhuil, cordero de secano y queso de Chanco: aportes para el estudio de patrimonio gastronómico y cultural de Chile”. Idesia, 35 (2) 17-26.

Lacoste, Pablo et al. (2015). "The rise and fall of Chanco cheese in Chile (1860-1930)". Ciencia e Investigación Agraria, 42 (1), 85-96.

Lacoste, Pablo et al. (2014). "Genesis and identity of Chanco cheese (Chile 1750-1860) Contribution to the study of Appellations of Origin in Latin America". Ciencia e Investigación Agraria, 41 (3), 317-325.

León, Leonardo (2001). Los señores de la cordillera y las pampas: los pehuenches de Malalhue 1770-1800. Mendoza: Universidad de Congreso.

Levaggi, Abelardo (2000). Paz en la frontera. Historia de las relaciones diplomáticas con las comunidades indígenas en la Argentina (siglos XVI-XIX). Buenos Aires: Universidad del Museo Social Argentino.

Maza, Juan Isidro (1991). Malargüe. Mendoza: Universidad Nacional de Cuyo-FFyL.

Ministerio de Obras Públicas (2017). Informe estadístico de los flujos de personas y vehículos por el Paso Pehuenche - Ruta Internacional 115CH. Santiago: MOP.

Núñez, Emiliano y Lacoste, Pablo (2017). "Historia de la chupalla: sombrero de paja típico del campesino chileno”. Idesia, 35 (1), 97-106. 
Prieto, María del Rosario (2000). "Formación y consolidación de la sociedad en un área marginal del Reino de Chile". Anales de Arqueología y Etnología, 55, 4-214.

Pueyrredón, Manuel (1947). Memorias inéditas. Prólogo y notas de Alfredo Villegas. Buenos Aires: Kraft.

Retamal Ávila, Julio (2004). "Economía y sociedad en el Maule siglo XVII". Estudios Coloniales, IV, Santiago, Universidad Andrés Bello, 77-146.

Rojas, Ricardo (1940). El santo de la espada. Vida de San Martín. Buenos Aires: Losada.

Sosa Morales, Narciso (1965). El muy magnífico señor don José Francisco Amigorena (Cuyo durante la Intendencia de Córdoba). Córdoba: Irineo Cangioli.

Silva, Osvaldo (1990). "Las etnias cordilleranas de los Andes centro-sur al tiempo de la conquista hispana y la cultura puelche". Cuadernos de Historia, 10, 51-67.

Undiano y Gastelú, Sebastián (1969). Proyecto de traslación de las fronteras de Buenos Aires al Río Negro y Colorado. En Pedro De Ángelis, Colección de Obras y Documentos. Buenos Aires: Plus Ultra, tomo II, 493-512.

Vera Rodríguez, José (2003). Sal y sociedad. Las salinas de Boyeruca 16442001. Tesis para optar al grado de Magister en Historia con Mención en Historia de Chile. Facultad de Filosofía y Humanidades, Universidad de Chile.

Vera Rodríguez, José (2011). La relevancia de la sal en las sociedades del Cono Sur de América. Rutas, traficantes, productores y usos, 1750-1850. Tesis doctoral inédita. Santiago de Chile: Universidad de Chile. 